\title{
BLICKDIAGNOSE
}

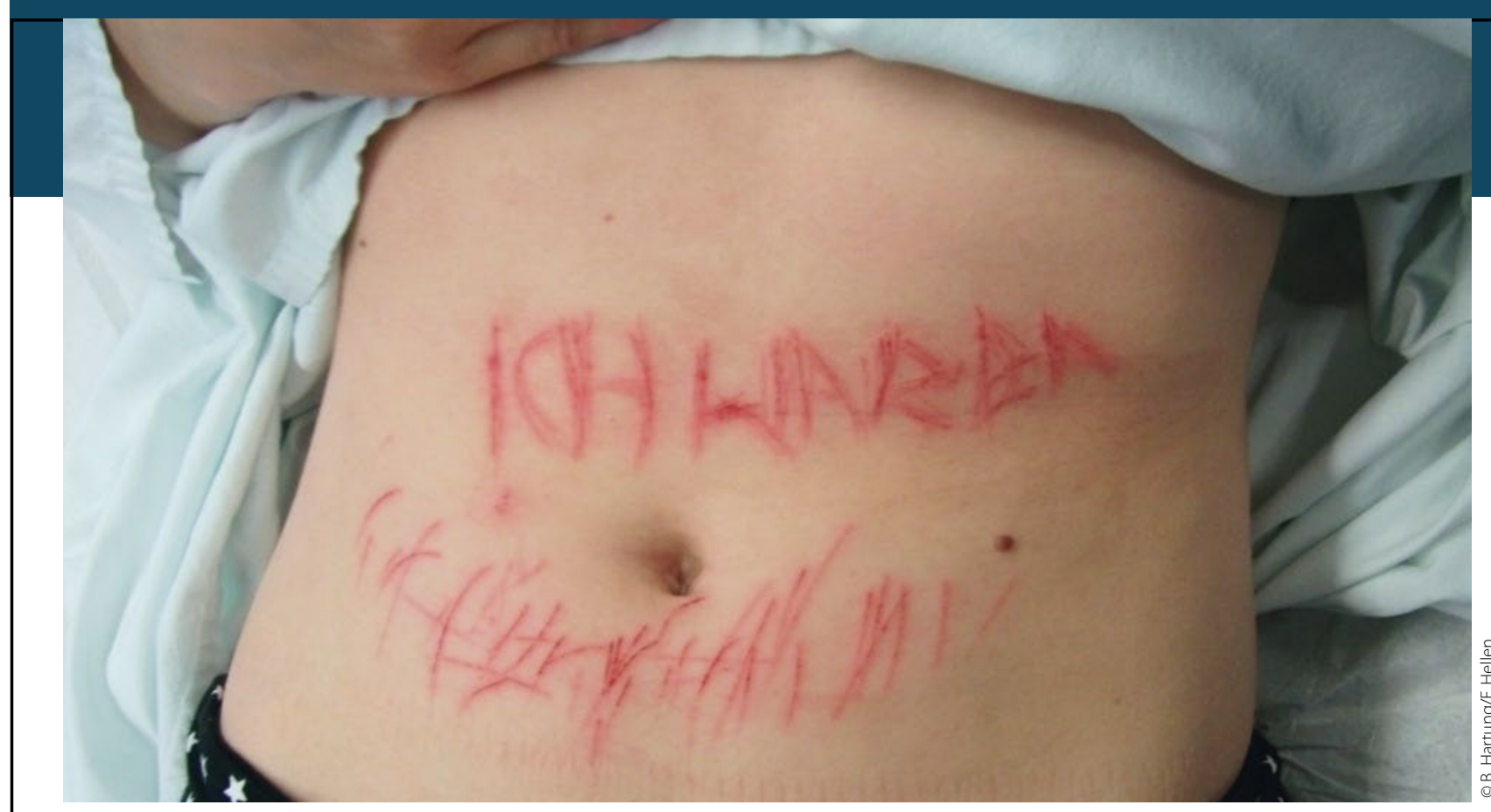

Schnittverletzungen bei einer 16-Jährigen

\section{Ist sie Opfer und/oder Täterin?}

Ein 16-jähriges Mädchen erschien bei der Polizei und erklärte, dass sie in einem öffentlichen Park von einem unbekannten, maskierten Mann gewaltsam festgehalten und an einen Baum gebunden worden sei. Der Mann habe ihr mit einem $20 \mathrm{~cm}$ langen Küchenmesser die obigen Schnittverletzungen zugefügt. Sie habe sich schließlich losreißen und davonlaufen können. Nachdem Strafanzeige gegen Unbekannt gestellt worden war, erfolgte eine rechtsmedizinische Begutachtung zur Dokumentation und gutachtlichen Interpretation.

- Die vorliegenden Verletzungen weisen nahezu alle wesentlichen Charakteristika einer Selbstbeschädigung auf. Es handelt sich um zahlreiche, durchweg oberflächliche, annähernd parallel angeordnete Schnitte. Die Verletzungen liegen in einem Bereich, der einer Selbstbeibringung leicht zugänglich und mit der Rechtshändigkeit des Mädchens gut vereinbar ist. Die Kleidung war unversehrt und die übrige körperliche Untersuchung zeigte keine Abwehrverletzungen oder andere Spuren einer äußeren Gewaltanwendung, was widersprüchlich zu dem geschilderten dramatischen Ablauf ist.

Unter selbstschädigendem Verhalten werden im Allgemeinen selbstbeigebrachte, direkte, körperliche Verletzungen ohne suizidale Intention verstanden. In der Vorgeschichte einer Selbstverletzung lassen sich nicht selten traumatisierende Erlebnisse finden. Abhängig von der individuellen Persönlichkeitsstruktur können Selbstverletzungen u.a. dazu eingesetzt werden, ein unerträgliches Gefühl innerer Leere zu durchbrechen oder um Wut gegenüber wichtigen, nahestehenden Dritten auszudrücken.

Im konkreten Fall wurde nach der Konfrontation des Mädchens mit der Tatsache, dass konkrete Hinweise auf ein selbstschädigendes Verhalten vorliegen, bekannt, dass das Mädchen vor längerer Zeit sexuell missbraucht worden war. Die Selbstverletzung habe ihrer Angabe nach dazu dienen sollen, auf ihre seelische Notlage aufmerksam zu machen.

Keywords: self-injury

- Dr. med. Benno Hartung: Institut für Rechtsmedizin, Universitätsklinikum Düsseldorf, Dr. med. Florence Hellen: LVR-Klinikum Düsseldorf, Universität Düsseldorf

\section{Info}

Weitere Blickdiagnosen finden Sie auch im Internet unter: http://www.springermedizin.de/ blickdiagnosen-aus-der-praxis/307330.html 